\title{
The Effects of Nicardipine on the Onset Time and Intubating Conditions of Cisatracurium
}

Pornwicha Chumak*, M.D., Sahawat Thertchanakun, M.D., Wirat Wasinwong, M.D., Prae Plansangkate, M.D., Sasithorn Mahatthanathporn, Amphan Chantarokorn

Department of Anesthesiology, Faculty of Medicine, Prince of Songkla Unversity, Songkhla, Thailand

${ }^{*}$ Corresponding author: Pornwicha Chumak, M.D., Department of Anesthesiology, Faculty of Medicine, Prince of Songkla Unversity, Songkhla, Thailand; Tel: + 66896543229; E-mail: pok_pwc@hotmail.com

Received: June 05, 2019; Accepted: June 12, 2019; Published: July 04, 2019;

\begin{abstract}
Purpose: Both Cisatracurium and Rocuronium are intermediate-acting, neuromuscular blocking agents, commonly used worldwide. Nicardipine has been reported to shorten the onset time of Rocuronium. However, the molecular structure of Cisatracurium is different from that of Rocuronium, thus, the aim of this study is to examine the effects of Nicardipine on the onset time and intubating conditions of Cisatracurium.

Methods: Ninety-nine patients were randomized into one of three groups; NSS (C group), Nicardipine $10 \mathrm{mcg} / \mathrm{kg}$ (N10 group), and Nicardipine 20 $\mathrm{mcg} / \mathrm{kg}$ (N20 group). After which, these patients were received the study drugs, according to the group they were assigned as, intravenously before the induction of anesthesia. Train of Four (TOF) ratio or count, blood pressure, pulse rate, laryngoscopic view, grade of intubation, intubating conditions, minimal mean arterial pressure, total propofol, and vasopressors doses were recorded.

Results: The onset times of Cisatracurium were 420, 420, and 360 seconds in the C, N10, and N20 groups respectively, with a p-value of 0.636, while, intubating conditions were acceptable in $93.8,96.8$ and $100 \%$ respectively with a p-value of 0.771 . Heart rates were higher in the N10 and N20 groups than that of those in the C group. Additionally, mean arterial pressures were lower in N20 group than both N10 and C groups, which were comparatively the same. Total propofol, ephedrine and atropine doses were similar within all groups.
\end{abstract}

Conclusions: The use of Nicardipine neither reduces the onset time, nor improves intubating conditions of Cisatracurium. However, Nicardipine, probably, attenuates a hypertensive response after intubation.

Keywords: Cisatracurium, Nicardipine, Onset time, Intubation, Intubating condition

\section{Introduction}

Both cisatracurium and rocuronium are intermediate-acting, neuromuscular blocking agents, commonly used worldwide. Cisatracurium has a unique elimination property, with no histamine release, however, it has slow onset time. Several techniques have been reported to shorten the onset time of cisatracurium such as high dose cisatracurium [1], cisatracurium priming [2], rocuronium priming [3,4], ephedrine [5], and ketamine [6]. These techniques were associated with their own limitations such as prolonged duration [1$4]$, or the need to use combination drugs $[5,6]$.

Multiple in-vitro and animal studies showed that calcium channel blockers potentiated non-depolarizing neuromuscular block, possibly by blocking L-type calcium channel or altering presynaptic calcium or altering acetylcholine release or postjunctional interaction [7-9]. Nicardipine has been shown to reduce the onset time of rocuronium [10], and improve hemodynamic stability after intubation [11]. However, the structure of cisatracurium differs from rocuronium. Thus, the aim of this study is to examine the effects of nicardipine on the onset time, and intubating conditions of cisatracurium.

\section{Methods}

After the approval from Office of Human Research Ethics Committee, faculty of medicine, Prince of Songkla University (REC 59-402-08-1) and study had been approved for registration at Thai Clinical Trial Registry (TCTR2017328002). This study was conducted at the operating theater of Songklanagarind Hospital, Thailand, from April 2017 to September 2017. Subjects were chosen from the elective schedule of the operations which required general anesthesia with oroendotracheal tube. The eligible patients were 18-65 years old, had ASA physical status 1 or 2 , and normal blood pressure. The exclusion criteria were patients with cardiac diseases, history of allergy to nicardipine or cisatracurium, history of malignant hyperthermia or neuromuscular diseases, pregnant or morbidly obese (BMI $\geq 35 \mathrm{~kg} /$ $\mathrm{m}^{2}$ ) patients, and patients who could not communicate.

The informed consent was obtained by the research team. All patients were received pre-medication as appropriate. The patients were then randomized into 3 groups: control group (C group), nicardipine $10 \mathrm{mcg} / \mathrm{kg}$ (N10 group), and nicardipine $20 \mathrm{mcg} / \mathrm{kg}$ (N20 group). The study drugs were prepared by the research team, not involving in the patient care. The solution of the control group 
was normal saline (NSS) $10 \mathrm{~mL}$, while the solution of the other two groups were calculated nicardipine based on the patients' actual body weight, diluted with NSS to the total volume of $10 \mathrm{~mL}$. The diluted mixture had clear color, similar to NSS. The patients were randomized by block-of-six randomization. Upon arriving at the operating theater, pulse oximetry, noninvasive blood pressure, 3-lead electrocardiograms, and nerve stimulator (TOF-Watch SX ${ }^{\circledR}$, Organon, Ireland) were monitored. The site of the nerve stimulator was at the adductor pollicis muscle.

A bolus of $7 \mathrm{~mL} / \mathrm{kg}$ of isotonic crystalloid were given to all patients, while they were being pre-oxygenated with $100 \%$ oxygen for 5 minutes. Then, the patients were received the study drugs according to their groups. After one minute, the patient was induced with fentanyl 1.5 $\mathrm{mcg} / \mathrm{kg}$, propofol $2 \mathrm{mg} / \mathrm{kg}$ intravenously. Additional propofol could be added by the attending anesthesiologist, if the depth of anesthesia was inadequate. When the patients lost their consciousness, manual facemask ventilation was performed, three breaths of end tidal Carbon dioxide were identified as adequate ventilation, at this moment cisatracurium $0.15 \mathrm{mg} / \mathrm{kg}$ was injected intravascularly.

During the induction, the vital signs were recorded at 1 minute interval until five minutes after intubation. The Train of Four (TOF) ratio or counts were recorded after cisatracurium injection every 15 seconds twice then every 30 seconds until 3 minutes after cisatracurium injection. The intubation commenced when TOF count $=0$ or at 3 minutes after cisatracurium injection if TOF count was still present. If the intubation happened before $\mathrm{TOF}$ count $=0$, additional TOF ratio would be recorded at 1-minute interval until 6 minutes after the intubation. The intubation was performed by anesthesia providers with at least a year of experience in anesthesia service, using a Macintosh size 3 laryngoscopic blade, and an appropriate size of endotracheal tube. After the intubation, anesthesia was maintained with sevoflurane in a gas mixture of air and oxygen, and fentanyl or morphine with target of end tidal sevoflurane of 1 MAC age-adjusted value.

Hypotension, defined as Mean Arterial Pressure (MAP) $<20 \%$ of baseline for 60 seconds, was treated with norepinephrine 5-10 mcg or ephedrine 3-6 mg intravenous bolus. Bradycardia, defined as heart rate $<50 \mathrm{bpm}$ for 60 seconds, was treated with atropine 0.3-0.6 mg intravenous bolus. Total propofol, ephedrine, norepinephrine, and atropine doses within 30 minutes were recorded. Also, minimum blood pressure within 30 minutes after cisatracurium injection was recorded.

Laryngoscopic view was graded using Cormack-Lehane classification, while intubating condition was graded as excellent, good or poor [12] (Table 1). Excellent and good intubating conditions were classified as clinically acceptable, while poor intubating condition was clinically unacceptable.

The primary outcome of this study was the onset time of cisatracurium, which was defined as a duration since cisatracurium injection until the TOF count $=0$. Secondary outcomes were intubation grades, intubating conditions, and hemodynamic value after intubation.
Table 1. Evaluation of intubating conditions

\begin{tabular}{|l|l|l|l|}
\hline \multicolumn{1}{|c|}{ Variable assessed } & \multicolumn{2}{c|}{ Clinically acceptable } & \multicolumn{1}{c|}{$\begin{array}{c}\text { Not clinically } \\
\text { acceptable }\end{array}$} \\
\hline & Excellent & Good & Poor \\
\hline Laryngoscopy & Easy & Fair & Difficult \\
\hline $\begin{array}{l}\text { Vocal cords position } \\
\text { Reaction to insertion of } \\
\text { the tracheal tube and cuff } \\
\text { inflation } \\
\text { (Diaphragmatic movement/ } \\
\text { coughing) }\end{array}$ & None & $\begin{array}{l}\text { Intermediate/ } \\
\text { moving }\end{array}$ & Closed \\
\hline
\end{tabular}

The sample size was calculated by two independent means, two-tailed test, formula; based on previous data [10]. Those authors reported that nicardipine $20 \mathrm{mcg} / \mathrm{kg}$ could shorten the onset of rocuronium from 204 seconds to 141.2 seconds. Alpha error was 0.05 , whilst $B$ error was 0.2 . The calculated sample size per group was 30 , after adding $10 \%$ dropout the final sample size was 33 subjects per group. Since the study of the $10 \mathrm{mcg} / \mathrm{kg}$ of nicardipine group was not available, similar sample size was inferred. Data was analyzed by repeated measured analysis, performed by $\mathrm{R}$ language, version 2.13.0. Categorical variables were compared by Chi-square or Fisher's exact test, whilst continuous variables were compared by ANOVA F-test, or Kruskal Wallis test. A p-value of less than 0.05 was considered statistically significant.

\section{Results}

Ninety-nine patients were enrolled in this study. The dropout rates and reasons are shown in Figure 1. A patient in the N20 group, was excluded from the study due to the clinical suspicion of anaphylaxis including hypotension, rash and wheezing. Later, she was confirmed to be allergic to cisatracurium by skin prick test. Other patients' exclusion was due to multiple intubation attempts. Patients' characteristics were similar among three groups, except that there were more male patients in the N10 group (Table 2).

Although, the onset time was shortest in the N20 group, the onset times were not statistically different among the three groups. Interestingly, within 5 minutes after cisatracurium injection, the probability that the TOF would be zero were $18.6 \%, 41.9 \%$, and $38.7 \%$ in the C, N10, and N20 groups respectively with a p-value of 0.0498 . By comparing the $\mathrm{N} 10$ and $\mathrm{C}$ groups, the p-value was 0.042 , while comparing the $\mathrm{N} 20$ and $\mathrm{C}$ groups, the p-value was 0.075 (Figure 2). Intubating conditions were improved in the N10 and N20 groups, however, with no statistically significance. Laryngoscopic views were also similar among three groups. Only two patients received atropine 0.3 and $0.6 \mathrm{mg}$ in the $\mathrm{N} 20$ group. While one patient received norepinephrine $10 \mathrm{mcg}$ in both N10 and N20 groups. Also, propofol doses were comparable (Table 3 ).

Blood pressures, heart rates after induction were shown in Figure 3. Mean Arterial Pressure (MAP) at baseline were 94.8, 93.4, and $90.9 \mathrm{mmHg}$ in the $\mathrm{C}, \mathrm{N} 10$, and $\mathrm{N} 20$ groups, respectively, while baseline heart rate (HR) were 80.1, 82.5, and 77.9, respectively. Mean 
MAP in the N20 group was significantly lower at 1 minute after induction and at 1 minute after intubation than those in the $\mathrm{C}$ group, which were 63.8, and $87.7 \mathrm{mmHg}$ versus 79.5 , and $102.1 \mathrm{mmHg}$ respectively (p-value $<0.001$, and 0.014 ).

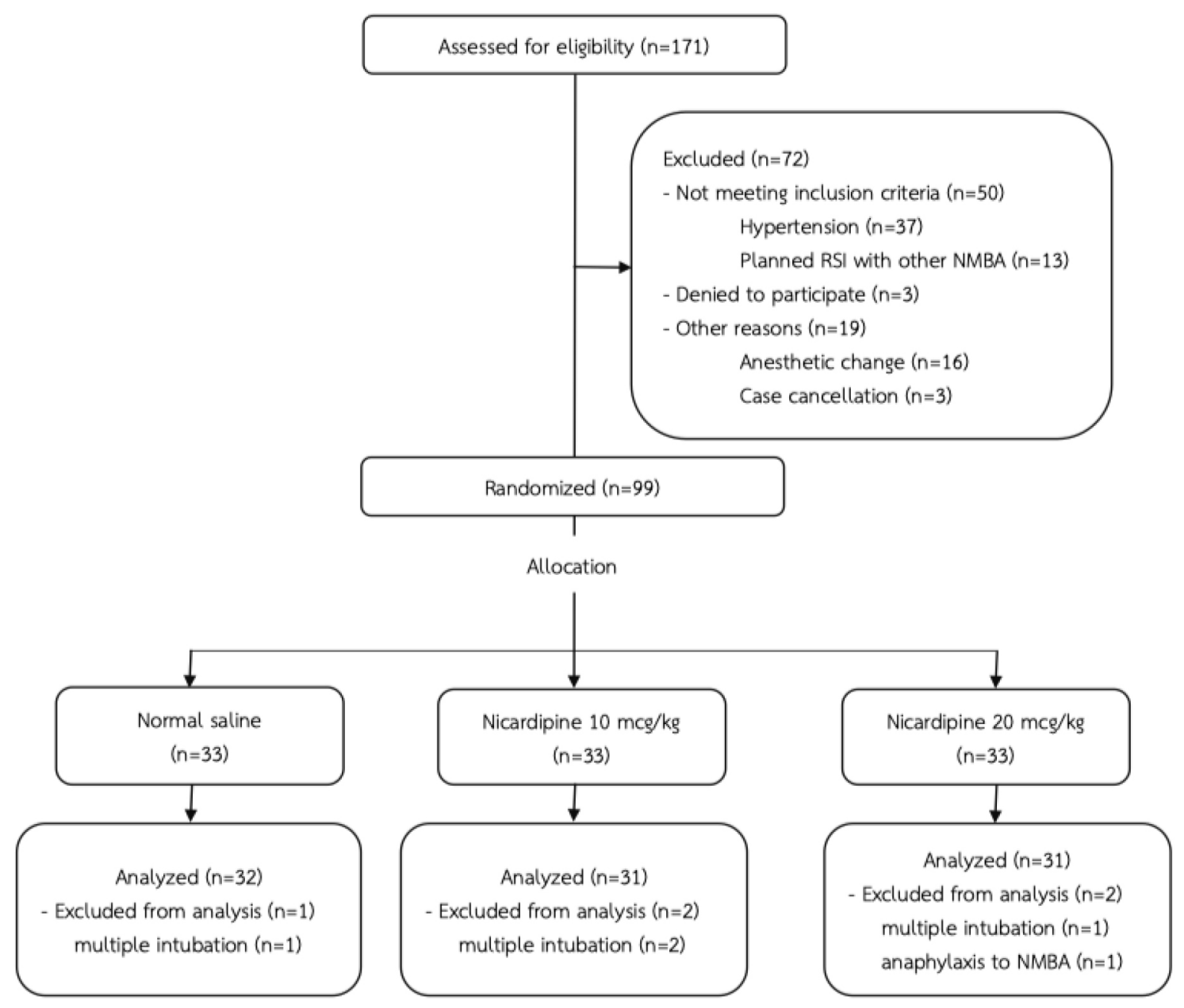

Figure 1. CONSORT flow diagram

RSI $=$ Rapid Sequence Induction, NMBA = Neuromuscular Blocking Agent

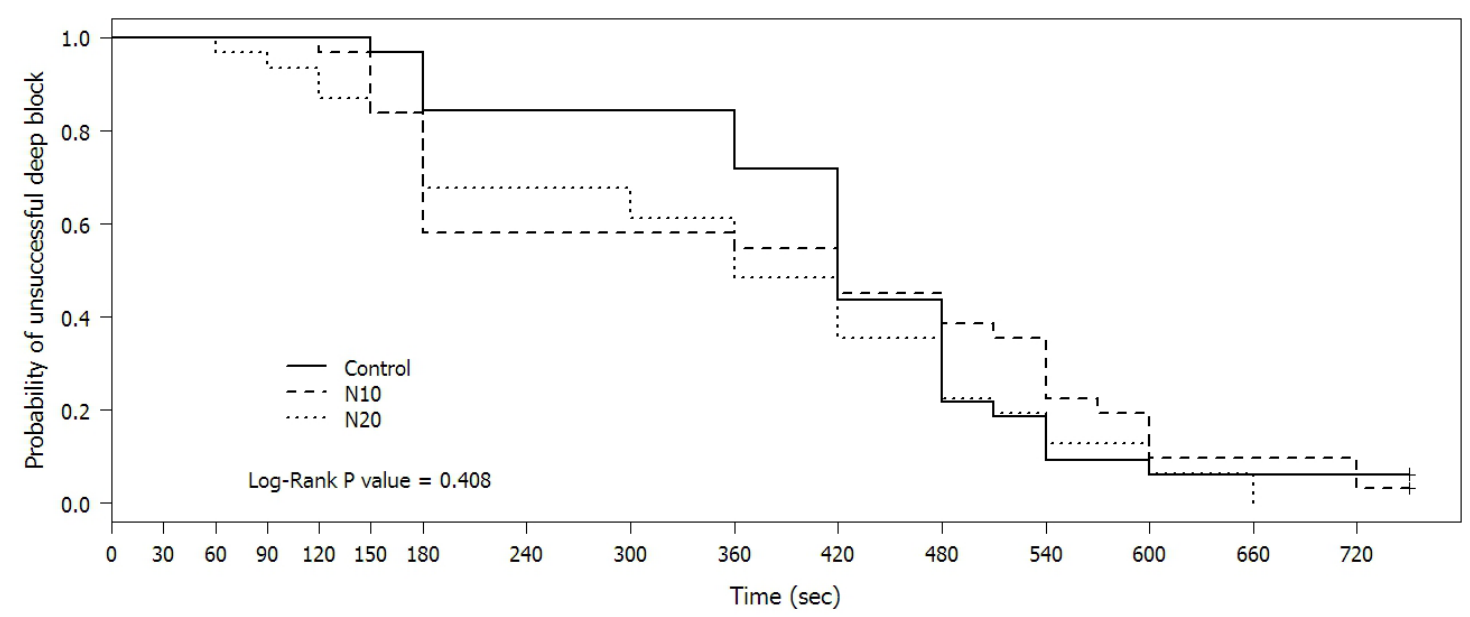

Figure 2. Probability of unsuccessful deep block

defining as TOF count $>0$ after cisatracurium injection 

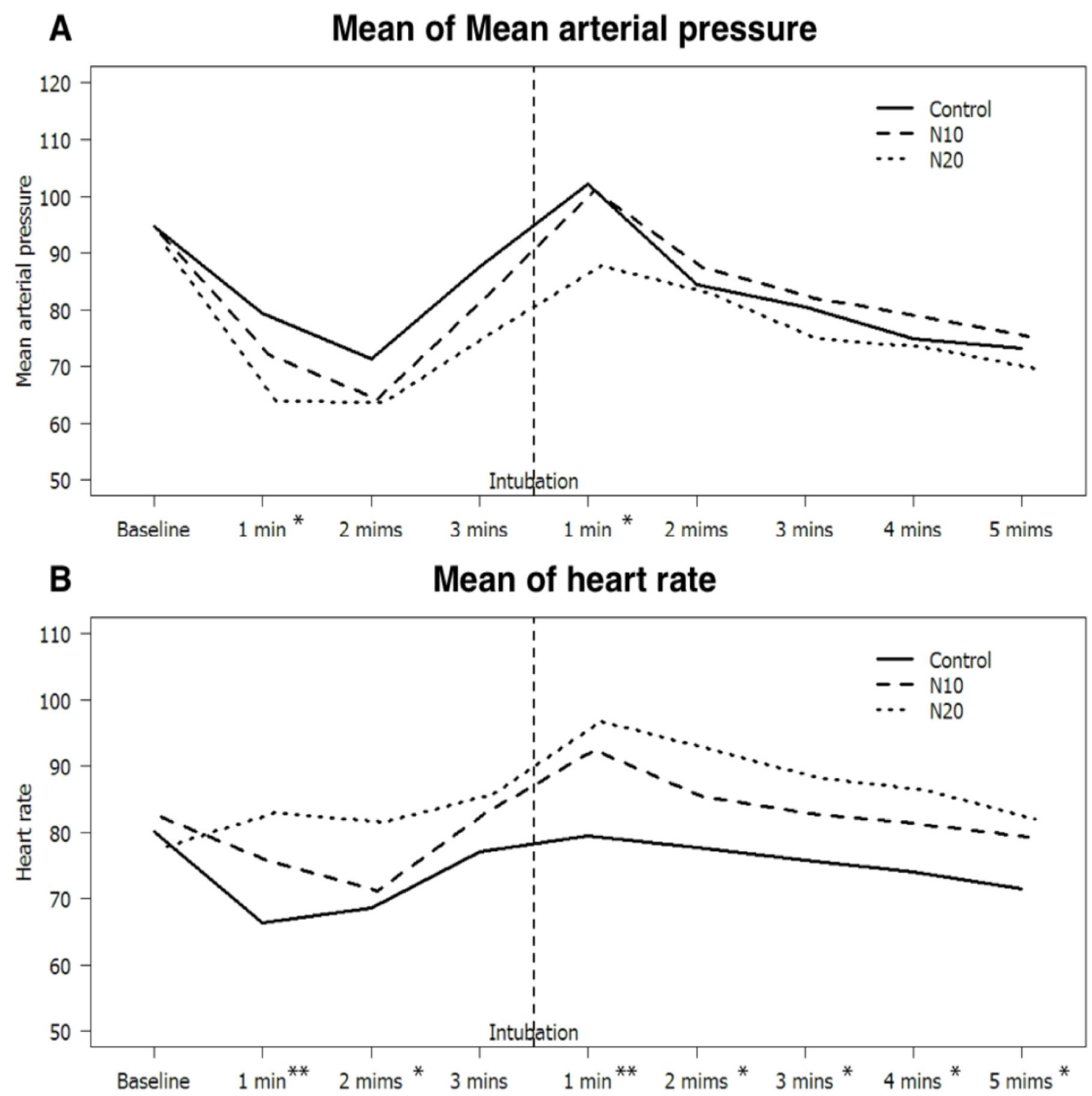

Figure 3. (A) Mean Arterial Pressure, (B) and heart rate since after induction Changes in (A) Mean Arterial Pressure, (B) and heart rate since after induction until 5 minutes after intubation, the numbers before the intubation are the duration after injection of study drugs, while the numbers after the intubation are the duration after intubation.

* p-value $<0.05$ when compared group $\mathrm{N} 20$ vs C

** p-value $<0.05$ when compared group N20 vs C and group N10 vs C 
Table 2. Patients characteristics

\begin{tabular}{|c|c|c|c|c|}
\hline & $\underset{(n=32)}{C}$ & $\begin{array}{c}N 10 \\
(n=31)\end{array}$ & $\begin{array}{c}\mathrm{N} 20 \\
(\mathrm{n}=\mathbf{3 1})\end{array}$ & p-value \\
\hline Sex & & & & 0.032 \\
\hline Male & $5(15.6 \%)$ & $14(45.2 \%)$ & $8(25.8 \%)$ & \\
\hline Female & $27(84.4 \%)$ & $17(54.8 \%)$ & $\begin{array}{c}23 \\
(74.2 \%)\end{array}$ & \\
\hline $\mathrm{Age}^{\mathrm{a}}$ & $46.3 \pm 11.9$ & $45.7 \pm 12.2$ & $\begin{array}{c}41.5 \pm \\
11.2\end{array}$ & 0.211 \\
\hline Body weight $^{\mathrm{a}}(\mathrm{kg})$ & $59.6 \pm 10$ & $59.7 \pm 19.8$ & $60.5 \pm 7.1$ & 0.922 \\
\hline Height $^{\mathrm{a}}(\mathrm{cm})$ & $158.7 \pm 6.3$ & $159.7 \pm 7.8$ & $\begin{array}{c}160.5 \pm \\
7.9\end{array}$ & 0.558 \\
\hline $\mathrm{BMI}^{\mathrm{a}}\left(\mathrm{kg} / \mathrm{m}^{2}\right)$ & $23.6 \pm 3.5$ & $23.6 \pm 3.6$ & $23.5 \pm 2.9$ & 0.988 \\
\hline ASA classification & & & & 0.520 \\
\hline 1 & $9(28.1 \%)$ & $5(16.1 \%)$ & $7(22.6 \%)$ & \\
\hline 2 & $23(71.9 \%)$ & $26(83.9 \%)$ & $\begin{array}{c}24 \\
(77.4 \%)\end{array}$ & \\
\hline $\begin{array}{l}\text { Intubator experience } \\
\text { (years) }\end{array}$ & $3(2,5)$ & $3(2.5,5)$ & $3(2.5,5)$ & 0.961 \\
\hline Operation type & & & & 0.582 \\
\hline General surgery & $6(18.8 \%)$ & $10(32.3 \%)$ & $5(16.1 \%)$ & \\
\hline $\begin{array}{l}\text { Otolaryngologic } \\
\text { surgery }\end{array}$ & $5(15.6 \%)$ & $9(29 \%)$ & $5(19.4 \%)$ & \\
\hline Urologic surgery & $1(3.1 \%)$ & $1(3.2 \%)$ & $3(9.7 \%)$ & \\
\hline Plastic surgery & $1(3.1 \%)$ & $0(0 \%)$ & $2(6.5 \%)$ & \\
\hline $\begin{array}{l}\text { Gynecologic } \\
\text { surgery }\end{array}$ & $12(37.5 \%)$ & $8(25.8 \%)$ & $\begin{array}{c}11 \\
(35.5 \%)\end{array}$ & \\
\hline $\begin{array}{l}\text { Orthopedic } \\
\text { surgery }\end{array}$ & $3(9.4 \%)$ & $0(0 \%)$ & $1(3.2 \%)$ & \\
\hline Eye surgery & $4(12.5 \%)$ & $3(9.7 \%)$ & $3(9.7 \%)$ & \\
\hline
\end{tabular}

Data are presented as frequency (percentage) format unless stated otherwise.

${ }^{a}$ Data are presented as mean \pm Standard Deviation

${ }^{\mathrm{b}}$ Data are presented as median (Interquartile range)

For heart rate comparison, between the N20 and C groups, the heart rates were significantly greater except at 3 minutes after induction ( $p$-value $<0.05$ ). While, the heart rates in the N10 group were faster than those in the $\mathrm{C}$ group only at 1 minute after induction and 1 minute after intubation, which were 75.7 , and 92.5 versus 66.4, and 79.5 beats per minute ( $\mathrm{p}$-value $<0.05$ ).

\section{Discussion}

Overall, our results show that nicardipine could not significantly shorten the onset time of cisatracurium, whereas previous data reported that nicardipine $20 \mathrm{mcg} / \mathrm{kg}$ administered at 1 minute before induction could shorten the onset time of rocuronium [10, 13]. Surprisingly, when considering only within 5 minutes after cisatracurium injection, nicardipine at the dose of $10 \mathrm{mcg} / \mathrm{kg}$ improved the probability of successful deep block. We proposed 2 possible explanations. First, we had not chosen the optimal dose to produce the neuromuscular blockade potentiation. Second, nicardipine may only work with the aminosteroidal structure, but not the benzyl-isoquinolinium structure of cisatracurium.

Baseline patients' characteristics were similar among the three groups, except for the gender in the N10 group. There were slightly more male patients in the N10 group. Despite this imbalance, the results seemed not to be affected. Adamus $M$ and colleagues demonstrated that gender did not affect either onset or duration of cisatracurium [14].

Table 3. Comparisons of outcomes

\begin{tabular}{|c|c|c|c|c|}
\hline & $\underset{(n=32)}{C}$ & $\begin{array}{c}N 10 \\
(n=31)\end{array}$ & $\begin{array}{c}\mathrm{N} 20 \\
(\mathrm{n}=31)\end{array}$ & p-value \\
\hline Onset time $^{\mathrm{b}}$ (seconds) & $\begin{array}{c}420 \\
(360,480)\end{array}$ & $\begin{array}{c}420 \\
(180,540)\end{array}$ & $\begin{array}{c}360 \\
(180,480)\end{array}$ & 0.636 \\
\hline Laryngoscopic view & & & & 0.918 \\
\hline Grade 1 & $\begin{array}{c}18 \\
(56.2 \%)\end{array}$ & $18(58.1 \%)$ & $20(64.5 \%)$ & \\
\hline Grade 2 & $\begin{array}{c}12 \\
(37.5 \%)\end{array}$ & $11(35.5 \%)$ & $9(29 \%)$ & \\
\hline Grade 3 & $1(3.1 \%)$ & $2(6.5 \%)$ & $2(6.5 \%)$ & \\
\hline Grade 4 & $1(3.1 \%)$ & $0(0 \%)$ & $0(0 \%)$ & \\
\hline Intubation grade & & & & 0.112 \\
\hline Excellent & $\begin{array}{c}19 \\
(59.4 \%)\end{array}$ & $26(83.9 \%)$ & $25(80.6 \%)$ & \\
\hline Good & $\begin{array}{c}11 \\
(34.4 \%)\end{array}$ & $4(12.9 \%)$ & $6(19.4 \%)$ & \\
\hline Poor & $2(6.2 \%)$ & $1(3.2 \%)$ & $0(0 \%)$ & \\
\hline Intubating condition & & & & 0.771 \\
\hline $\begin{array}{l}\text { Clinically } \\
\text { acceptable }\end{array}$ & $\begin{array}{c}30 \\
(93.8 \%)\end{array}$ & $30(96.8 \%)$ & $31(100 \%)$ & \\
\hline $\begin{array}{l}\text { Not clinically } \\
\text { acceptable }\end{array}$ & $2(6.2 \%)$ & $1(3.2 \%)$ & $0(0 \%)$ & \\
\hline $\begin{array}{l}\text { Total propofol dose } \\
(\mathrm{mg})\end{array}$ & $\begin{array}{c}150 \\
(130,185)\end{array}$ & $\begin{array}{c}150 \\
(126,160)\end{array}$ & $\begin{array}{c}150 \\
(130,190)\end{array}$ & 0.683 \\
\hline $\begin{array}{l}\text { Total ephedrine dose } \\
\text { (mg) }\end{array}$ & $0(0,0)$ & $0(0,6)$ & $0(0,3)$ & 0.587 \\
\hline $\begin{array}{l}\text { Lowest MAP } \\
(\mathrm{mmHg})\end{array}$ & $\begin{array}{c}64.2 \pm \\
11.2\end{array}$ & $64 \pm 10.9$ & $61.5 \pm 12.6$ & 0.596 \\
\hline
\end{tabular}

Data are presented as frequency (percentage) format unless stated otherwise.

MAP $=$ Mean Arterial Pressure

* Lowest MAP stated here is the lowest MAP within 30 minutes after the study drug injection

${ }^{a}$ Data are presented as mean \pm Standard Deviation

${ }^{\mathrm{b}}$ Data are presented as median (Interquartile range)

Regarding the intubating conditions, our results showed that clinically acceptable intubating conditions in the N20 group were slightly better than other groups. Additionally, more subjects achieved excellent intubation grades in both the N10 and N20 groups. Unfortunately, these effects did not reach the statistically significance threshold. Our results support previous findings in the literature by 
Lee $\mathrm{JH}$ and colleagues, when they used lidocaine $1 \mathrm{mg} / \mathrm{kg}$ in their study [13]. In contrast, Lee SY and colleagues found that nicardipine improved intubating conditions of rocuronium [10]. It should be noted that they did not use either fentanyl or lidocaine in their study. Thus, from these results, it seemed that nicardipine provided no added benefit in improving intubating conditions, when either fentanyl or lidocaine were used.

Nicardipine at the dose of $20 \mathrm{mcg} / \mathrm{kg}$ in our study decreased MAP after intubation, with concomitant tachycardia, in contrast, the dose of $10 \mathrm{mcg} / \mathrm{kg}$ failed to produce the same effect. This result was consistent with the previous reports $[10,11,13,15-17]$. It should be noted that the patterns of blood pressure changes were similar in every group. From these results, it seemed that nicardipine at the dose of $20 \mathrm{mcg} / \mathrm{kg}$ had attenuated the hypertensive response after intubation, however it produced a tachycardia response instead.

Our study has several strengths, the two different doses of nicardipine were used to investigate their effects. Also, our actual sample size is adequate even after the dropout. Finally, our study was a double-blinded randomized controlled study, and the study drugs were carefully prepared so the color of the drugs cannot be visually distinguished.

One downside regarding our methodology is that the anesthesia personnels who intubated the patients, consisted of anesthesiologists, anesthesia residents, and nurse anesthetists. The different level of experiences may affect the laryngoscopy difficulty, even the working experience years were similar in all groups. Furthermore, our study consists of only ASA physical status 1 and 2 patients only, so the results should not be generalized to patients with cardiovascular diseases. Finally, we choose to monitor TOF response at the adductor pollicis muscles to follow the guideline [12]. Although the onset of the neuromuscular blockade would be faster if we choose the orbicularis oculi muscles [18], the intubating conditions in our study would be different [19]. Thus, our absolute value of the onset time of cisatracurium need to be interpreted with caution.

In conclusion, nicardipine at the dose of 10 , and $20 \mathrm{mcg} / \mathrm{kg}$ can neither shorten the onset time of cisatracurium nor improve intubating conditions of cisatracurium, although the dose of $20 \mathrm{mcg} /$ $\mathrm{kg}$ may attenuate hypertensive response after intubation. Higher probability of successful deep block within 5 minutes by nicardipine at the dose of $10 \mathrm{mcg} / \mathrm{kg}$ is an interesting issue for future research.

\section{Acknowledgements}

First and foremost the authors would like to express our sincere gratitude to all of our colleagues for their cooperation. This study could not have been successfully completed without their kind support, especially Nannapat Pruphetkaew who helped us calculate the sample size.

\section{Conflict of Interest Statement}

This research did not receive any specific grant from funding agencies in the public, commercial, or not-for-profit sectors.

\section{References}

1. Lighthall GK, Jamieson MA, Katolik J, Brock-Utne JG. (1999) A Comparison of the Onset and Clinical Duration of High Doses of Cisatracurium and Rocuronium. J Clin Anesth. 11: 220-5. [Crossref]

2. Deepika K, Kenaan CA, Bikhazi GB, Martineau DB. (1999) Influence of the Priming Technique on Pharmacodynamics and Intubating Conditions of Cisatracurium. $J$ Clin Anesth. 11: 572-5. [Crossref]

3. Mak PH, Irwin MG. (2004) The effect of cisatracurium and rocuronium on cisatracurium precurarization and the priming principle. $J$ Clin Anesth. 16: 83-7. [Crossref]

4. Lin SP, Chang KY, Chen YJ, Lin SM, Chang WK, Chan KH, et al. (2008) Priming with Rocuronium to Accelerate the Onset Time of Cisatracurium During Intubation. J Chin Med Assoc. 72: 15-9. [Crossref]

5. Leykin Y, Dalsasso M, Setti T, Pellis T. (2010) The effects of low-dose ephedrine on intubating conditions following low-dose priming with cisatracurium. J Clin Anesth. 22: 425-31. [Crossref]

6. Ahn BR, Kim SH, Yu BS, Lim KJ, Sun JJ. (2012) The effect of low dose ketamine and priming of cisatracurium on the intubating condition and onset time of cisatracurium. Korean J Anesthesiol. 63: 308-13. [Crossref]

7. Sekerci S, Tulunay M. (1996) Interactions of calcium channel blockers with nondepolarising muscle relaxants in vitro. Anaesthesia. 51: 140-4. [Crossref]

8. Anderson KA, Marshall RJ. (1985) Interactions between calcium entry blockers and vecuronium bromide in anaesthetized cats. Br J Anaesth. 57: 775-81. [Crossref]

9. Bikhazi GB, Leung I, Flores C, Mikati HM, Foldes FF. (1988) Potentiation of neuromuscular blocking agents by calcium channel blockers in rats. Anesth Analg. 67: 1-8. [Crossref]

10. Lee SY, Kim YH, Ko YK, Park SI, Lee JU, Chung WS, et al. (2016) Effects of nicardipine on the onset time and intubation conditions of rocuronium-induced neuromuscular blockade. J Clin Anesth. 32: 112-8. [Crossref]

11. Song D, Singh H, White PF, GAdhiali M, Griffin JD, Klein KW. (1997) Optimal Dose of Nicardipine for Maintenance of Hemodynamic Stability After Tracheal Intubation and Skin Incision. Anesth Analg. 85: 1247-51. [Crossref]

12. Fuchs-Buder T, Claudius C, Skovgaard LT, Eriksson LI, Mirakhur RK, VibyMogensen J. (2007) Good clinical research practice in pharmacodynamic studies of neuromuscular blocking agents II: the Stockholm revision. Acta Anaesthesiol Scand. 51: 789-808. [Crossref]

13. Lee JH, Kim Y, Lee KH, Rim SK, Lee JY, Lee C. (2015) The effects of nicardipine or esmolol on the onset time of rocuronium and intubation conditions during rapid sequence induction: a randomized double-blind trial. J Anesth. 29: 403-8. [Crossref]

14. Adamus M, Gabrhelik T, Marek O. (2008) Influence of gender on the course of neuromuscular block following a single bolus dose of cisatracurium or rocuronium. Eur J Anaesthesiol. 25: 589-95. [Crossref]

15. Omote K, Kirita A, Namiki A, Iwasaki H. (1992) Effects of nicardipine on the circulatory responses to tracheal intubation in normotensive and hypertensive patients. Anaesthesia. 47: 24-7. [Crossref]

16. Wig J, Sharma M, Baichoo N, Agarwal A. (1994) Nicardipine and verapamil attenuate the pressor response to laryngoscopy and intubation. Can J Anaesth. 41: 1185-8. [Crossref]

17. Mikawa K, Obara H, Kusunoki M. (1990) Effect of nicardipine on the cardiovascular response to tracheal intubation. Br J Anaesth. 64: 240-2. [Crossref]

18. Donati F, Meistelman C, Plaud B. (1990) Vecuronium neuromuscular blockade at the diaphragm, the orbicularis oculi, and adductor pollicis muscles. Anesthesiology. 73: 870-5. [Crossref]

19. Lee HJ, Kim KS, Jeong JS, Cheong MA, Shim JC. (2009) Comparison of the adductor pollicis, orbicularis oculi, and corrugator supercilii as indicators of adequacy of muscle relaxation for tracheal intubation. Br J Anaesth. 102: 869-74. [Crossref]

Citation:

Pornwicha Chumak, Sahawat Thertchanakun, Wirat Wasinwong, Prae Plansangkate, Sasithorn Mahatthanathporn, Amphan Chantarokorn (2019) The Effects of Nicardipine on the Onset Time and Intubating Conditions of Cisatracurium. J Clin Res Med Volume 2(3): 1-6. 